\title{
Physiology of Rice Sheath Blight Pathogen Rhizoctonia solani Kuhn towards Different Sources of Carbon, Nitrogen and Vitamins
}

\author{
Durga Prasad $^{1 *}$, Ramji Singh $^{2}$ and Ajay Tomer ${ }^{3}$ \\ ${ }^{1}$ Department of Plant Pathology, Banda University of Agriculture and Technology, \\ Banda-210001, UP, India \\ ${ }^{2}$ Department of Plant Pathology, S.V.P. University of Agriculture and Technology, \\ Meerut-250110, UP, India \\ ${ }^{3}$ Lovely Professional University, Jalandhar-144411, Punjab, India \\ *Corresponding author
}

\begin{tabular}{|c|}
\hline Keywords \\
\hline $\begin{array}{l}\text { Rice, Sheath blight, } \\
\text { Rhizoctonia solani, } \\
\text { Sclerotia, Czapek's, } \\
\text { Calcium pentothenate }\end{array}$ \\
\hline Article Info \\
\hline $\begin{array}{l}\text { Accepted: } \\
\text { 12 July } 2018 \\
\text { Available Online: } \\
10 \text { August } 2018\end{array}$ \\
\hline
\end{tabular}

\section{Introduction}

Rice production worldwide is affected by many biotic and abiotic stresses (Richa et al., 2016). Among biotic stresses, diseases are considered as major constraints for yield as 10 to 30 per cent of the annual rice harvest is lost

\section{A B S T R A C T}

Among the carbon sources, glucose supported highest weight of dried mycelium and maximum number of sclerotia formation followed by sucrose and maltose. The lactose supported least growth and also inhibitory for sclerotia formation. Out of four nitrogen sources, calcium nitrate supported highest weight of dried mycelium and maximum number of sclerotia followed by alanine. Urea exhibited inhibitory effect for sclerotia formation. In the vitamins, Thiamine supported highest weight of dried mycelium and maximum number of sclerotia followed by yeast extract. Biotin and inositol both were found to be inhibitory for growth and sclerotia formation as well. Combinations of fructose + glucose + lactose and sucrose + fructose + lactose resulted in such a highest level of growth and sclerotia formation. The combination of sucrose, fructose and glucose found to be inhibitory for growth and sclerotia formation both. Among the combinations of nitrogen sources, calcium nitrate + alanine + sodium nitrate supported highest growth and sclerotia formation followed by calcium nitrate + urea + alanine+ sodium nitrate. It was interesting to note that addition of urea in any combination had an inhibitory effect on growth and sclerotia formation. Among the combinations of vitamins; biotin + calcium pentothenate + thiamine resulted in highest growth, whereas highest sclerotia formation was noticed in yeast extract (multivitamins) supplemented medium. Biotin, thiamine and calcium pentothenate stimulated the mycelial growth, but addition of inositol was found to be inhibitory to the fungal growth and sclerotia formation. 
throughout the all rice growing areas, being most prominent where rice is grown under intense, cultivation systems (Eizenga et al., 2002). Although earlier considered a minor disease (Ramakrishnan, 1971), it has assumed the status of a major disease in the rice growing tracts of India (Roy, 1993) and, therefore, is one of the major biological constraints in the profitable rice production. This disease is particularly important in intensive rice cultivation systems (Savary and Mew, 1996; Gautam et al., 2003) and it can reduce yield up to $50 \%$ (Richa et al., 2016) under favorable epiphytotic conditions.

The disease is soil borne and the pathogen survives in the form of mycelium or sclerotia for longer period either in soil directly or in association with rice stubbles. The pathogen is imperfect in nature but its perfect stage belongs to Basidiomycetes. The pathogen is regarded as an unspecialized organism with indefinite pathogenic races (Kotasthane et al., 2004) having vast host ranges like cereals, pulses and vegetables of different taxonomic group. Under favorable conditions, the disease may progress in three ways, viz., inward, vertically and horizontally (Dasgupta, 1992 and Singh et al., 1989). Young mycelium observed as silvery, becoming yellow and brown with maturity, 8-12 $\mu \mathrm{m}$ broad and infrequently septate.

Three types of mycelium i.e. runner, lobate and moniloid were seen (Dasgupta, 1992). Sclerotia are superficial, more or less globose but flattened below, white when young, becoming brown or dark brown at maturity. The sclerotia of $R$. solani are brown to black composed of clusters of melanin-encrusted, thick walled cells, rich in nutrients, formed by repeated branching from short, thick, lateral hyphae. Disease severity is influence by the aggressiveness of the pathogen, sclerotial size and inoculum density which ultimately influence the inoculums potential. The aggressive isolates of $R$. solani produced severe symptoms than the less aggressive ones. Size of sclerotia was found to be directly correlated with the inoculum potential. Bigger sclerotia resulted in higher disease severity (Dasgupta, 1992). A positive correlation between number of viable sclerotia and disease severity has been reported by Hyakumachi and Ui (1982). $R$. solani exhibited different response towards different sources of nutrition viz. Carbon, Nitrogen and Vitamins (Sharma and Tripathi, 2002 and Chauhan, 2006). Determining the nutritional requirement of $R$. solani may help in better understanding of its epidemiology, pathogenicity and aggressiveness. With these mandates, the present investigations were therefore undertaken to determine the effect of various sources of Carbon, Nitrogen and vitamins and their various combinations as well on growth and sclerotia formation of $R$. solani.

\section{Materials and Methods}

Isolation, purification, identification and maintenance of $R$. solani

The culture of $R$. solani Kuhn used in the present investigation was isolated from the diseased rice plant cv. Pusa Basmati-1, which was collected from the students' instructional farm of Narendra Deva University of Agriculture and Technology, Kumarganj, Faizabad adopting standard procedure for isolation and purification. Identity of the causal organism i.e. $R$. solani was confirmed on the basis of morphological characteristics such as shape, size and colour of sclerotia, hyphal branching, septation and colour of mycelium, presence/absence of moniloid cells, growth rate etc, as per standard description given by Parmeter and Whitney (1970). Single sclerotial culture of $R$ solani was maintained on PDA for further various studies including pathogenicity test, In-vitro evaluation etc. 


\section{Effect of nutrients on growth and sclerotia} formation of $R$. solani

This study was conducted in Czapek's broth medium (Sucrose 30g, Sodium nitrate $2 \mathrm{~g}$, Dipotassium hydrogen orthrophosphate $1 \mathrm{~g}$, Magnesium sulphate $0.5 \mathrm{~g}$, Potassium chloride $0.5 \mathrm{~g}$, Ferrous sulphate $0.01 \mathrm{~g}$ and Deionized distilled water 1.0 litre) because this medium supports good growth of mycelium and sclerotia formation of $R$. solani and it is chemically defined as well. Each treatment was replicated four times with completely randomized design.

\section{Effect of carbon sources}

Four carbon sources (Table 1) viz., glucose, fructose, sucrose and lactose were tested for their suitability for the growth and sclerotia formation of $R$. solani. In present study, the sucrose was omitted from the basal medium and it was substituted with other carbon sources like glucose, fructose, or lactose to provide $12.61 \mathrm{~g}$ of carbon per liter of medium as per treatment need. Five possible combinations of all the four sugars were also tested (Table 4) for their effect on growth and sclerotia formation of $R$. solani. In combination of 4 carbon sources, the quantity of carbon (12.61g) per liter medium was provided @ $3.15 \mathrm{~g}$ per carbon source.

To provide $3.15 \mathrm{~g}$ carbon from each carbon source; 7.87, 7.87, 7.48 and $7.48 \mathrm{~g}$ Glucose, Fructose, Sucrose and Lactose, respectively, were added in one litre of medium. However, in combination of 3 carbon sources, the quantity of carbon (12.61g) per liter medium was provided @4.20 g per carbon source. To provide $4.20 \mathrm{~g}$ carbon from each carbon source; 10.5, 10.5, 10 and $10 \mathrm{~g}$ Glucose, Fructose, Sucrose and Lactose, respectively, were used in one litre of medium. Amount of each carbon source was determined according their molecular weight.

\section{Effect of nitrogen sources}

Four nitrogen sources (Table 2) viz., sodium nitrate, calcium nitrate, urea and alanine were tested for their suitability for growth and Sclerotia formation of $R$. solani in Czapek's broth medium. Quantity of nitrogen sources were determined on the basis of nitrogen content in the sodium nitrate, which was a constituent of basal medium and was substituted with other sources mentioned above to provide same amount of nitrogen as provided by the sodium nitrate i.e. $330 \mathrm{mg}$. in one liter medium. Five possible combinations of all the four sources of nitrogen were also tested (Table 5) for their effect on growth and sclerotia formation of $R$. solani. Amount of individual sources of nitrogen was determined in such a way that total amount of nitrogen in any mixture of different sources should not exceed $330 \mathrm{mg}$ and equal amount of nitrogen should be given by each individual source of nitrogen.

\section{Effect of vitamins}

Four vitamins (Table 3) viz., Biotin @

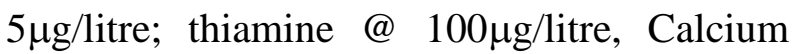
pentothenate@100 $\mu \mathrm{g}$ per litre and inositol @ 500 $\mu \mathrm{g} / \mathrm{litre}$ were tested for their suitability for growth and Sclerotia formation of $R$. solani. Vitamins quantity was decided according to Singh (1973). All these four vitamins mentioned above were also tested in different combination (Table 5) for their suitability for growth and sclerotia formation of $R$. solani. The yeast extract which is supposed to be a source of multi-vitamins @ 2 $\mathrm{g}$ per litre was taken as standard check, whereas, basal medium without any vitamins or yeast extract also served as another normal check. The vitamins and yeast extract were dissolved in deionized distilled water and added to the basal medium before autoclaving to give the final concentrations as mentioned above. 
Adjustment of $\mathbf{p H}$, autoclaving, inoculation and incubation

Hundred $\mathrm{ml}$ of medium was taken in $250 \mathrm{ml}$ volume conical flasks. Level of $\mathrm{pH}$ (6.5) was adjusted by adding $0.1 \mathrm{~N}-\mathrm{NaOH}$ and $\mathrm{HCl}$. The $\mathrm{pH}$ of solution (medium) was determined before and after sterilization by Backman $\mathrm{pH}$ meter. The flasks were sealed with cotton plug tightly. The flasks containing the media were sterilized in an autoclave at $15 \mathrm{lbs}$ for 20 minutes.

After autoclaving and proper cooling, the flasks containing medium supplemented with either nutrients or without nutrients were taken out of autoclave and placed into inoculation chamber under U.V. light and further more cooling for one hour. Thoroughly cooled flasks were inoculated with $5 \mathrm{~mm}$ diameter mycelial discs of $R$. solani in aseptic conditions and placed into an incubator maintained at $28+1^{\circ} \mathrm{C}$ for 14 days under dark conditions. At the end of incubation period, the weight of dried mycelium and number of sclerotia were recorded.

\section{Weight of dried mycelium and sclerotia count}

Mycelial mat were filtered through Whatman filter paper no. 2. Filter paper containing mycelial mat was washed thoroughly with distilled water to remove traces of chemicals associated with mycelial mat. Filter paper containing mycelial mat were dried at $60^{\circ} \mathrm{C}$ for $72 \mathrm{hrs}$ in oven. Subsequently, cooled in desiccator having anhydrous calcium chloride and accurately weighted on electronic balance. Weight of dried mycelium was calculated in mg by subtracting the weight of filter paper from total weight of filter paper containing mycelial mat. Sclerotia counting was done by qualitative assessment, giving $(+)$ and (-) signs, because exact number counting was not possible due to dense population of sclerotia in some of the treatments. The (-) signs indicate absence of sclerotia.

\section{Results and Discussion}

\section{Effect of carbon sources on $R$. solani}

Data indicate that (Table 1) glucose supported highest weight of dried mycelium $(271.25 \mathrm{mg}$ ), however sucrose too was found to be equally effective in supporting and enhancing the weight of dried mycelium $(270.50 \mathrm{mg})$ and it was at par with the glucose. Maltose was little less effective in supporting the growth $(183 \mathrm{mg})$ which is significantly less than the mycelial weight supported by glucose and sucrose. Lactose resulted in least weight of dried mycelium i.e. $123.50 \mathrm{mg}$ which was significantly less than the rest of carbon sources. Glucose and sucrose supported highest number of sclerotia followed by maltose. Lactose did not support the sclerotia formation.

\section{Effect of nitrogen sources on $R$. solani}

Among the nitrogen sources (Table 2), calcium nitrate was found to support highest weight of dried mycelium (641.25mg) and was significantly superior to the weight of dried mycelium exhibited by alanine, urea and sodium nitrate, respectively. The second highest weight of dried mycelium of Rhizoctonia solani was supported by alanine supplemented medium (433.50mg) and it was significantly higher than the mycelial weight $(270.50 \mathrm{mg})$ exhibited by sodium nitrate (check). However, urea was found to support least weight $(245.50 \mathrm{mg})$ of dried mycelium which was significantly less than the weight of dried mycelium exhibited by all other sources of nitrogen. Maximum number of sclerotia was supported by calcium nitrate and sodium nitrate. However, alanine also supported the sclerotia formation but it was comparatively less than those observed in calcium nitrate and 
sodium nitrate. Urea did not support the sclerotia formation because no sclerotia were observed in basal medium supplemented with urea.

\section{Effect of different vitamins on $\boldsymbol{R}$. solani}

Among three vitamins and two checks i.e. Czapek's medium without supplement and with yeast extract, the thiamine was found to support highest weight of dried mycelium i.e. $630.25 \mathrm{mg}$ (Table 3). The next highest weight of dried mycelium of $R$. solani was supported by yeast extract supplemented medium (Check-I) i.e. $344.00 \mathrm{mg}$. The mycelial weight exhibited by yeast extract was significantly less than that exhibited by thiamine but higher than the mycelial weight exhibited by (CheckII), biotin and inositol i.e. $270.50 \mathrm{mg}, 234.75$ $\mathrm{mg}$ and $226.25 \mathrm{mg}$, respectively. The mycelial weight exhibited by biotin and inositol were at par to each other. It was noticed that biotin and inositol both were found to be inhibitory for growth of $R$. solani because the weight of dried mycelium exhibited by Biotin or Inositol supplemented medium were significantly less that the weight of dried mycelium exhibited by the Czapek's medium where no vitamin or yeast extract was added. Among the different vitamins, thiamine supported highest number of sclerotia. However, yeast extract and inositol also supported the sclerotia formation but it was comparatively less than those observed in thiamine. Biotin did not supported the sclerotia formation because no sclerotia was observed in medium supplemented with biotin, rather biotin seems to be inhibitory for sclerotia formation because even the Czapek's medium without yeast extract also supported the sclerotia formation.

\section{Effect of different combination of carbon sources on $R$. solani}

Among the five combinations of carbon sources and check Czapek's medium containing sucrose (Table 4), the combination of fructose + glucose + lactose $(\mathrm{F}+\mathrm{G}+\mathrm{L})$ was found to support highest weight of dried mycelium (390.00 mg). The second and third highest weight of dried mycelium of $R$. solani i.e. $351.00 \mathrm{mg}$ and $295.00 \mathrm{mg}$ was supported by the combination of sucrose + fructose + lactose $(\mathrm{S}+\mathrm{F}+\mathrm{L})$ and sucrose + fructose + lactose + glucose $(\mathrm{S}+\mathrm{F}+\mathrm{L}+\mathrm{G})$ supplemented medium, respectively. The combination of carbon i.e. $\mathrm{S}+\mathrm{L}+\mathrm{G}$ and $\mathrm{S}+\mathrm{F}+\mathrm{G}$ were found to be inferior rather inhibitory for growth of $R$. solani as the weight of dried mycelium recorded in these combinations were significantly less than check. For sclerotia formation, combination of $\mathrm{F}+\mathrm{G}+\mathrm{L}$ was found to support the highest number and size of sclerotia of $R$. solani. However, the combination of $\mathrm{S}+\mathrm{F}+\mathrm{L}$ also supported the highest number of sclerotia, but the size of sclerotia was smaller as compared to those observed in combination $\mathrm{F}+\mathrm{G}+\mathrm{L}$. The combination of carbon sources i.e. $\mathrm{S}+\mathrm{F}+\mathrm{G}$ and $\mathrm{S}+\mathrm{L}+\mathrm{G}$ supported poor sclerotia formation as they were inferior to check.

\section{Effect of different combinations of nitrogen on $R$. solani}

Among the various combination of nitrogen sources (Table 5); Calcium Nitrate $(\mathrm{CN})+$ Alanine $(\mathrm{Al})+$ Sodium Nitrate $(\mathrm{SN})$ supported highest weight of dried mycelium (860mg) followed by $680.50 \mathrm{mg}$ resulted in combination calcium nitrate $(\mathrm{CN})+$ alanine $(\mathrm{Al})+$ sodium nitrate $(\mathrm{SN})+$ urea $(\mathrm{U})$. The combination Urea + Alanine + Sodium Nitrate resulted in 310.00 mg dried mycelium. Maximum number of sclerotia was noticed in the combination $\mathrm{CN}+\mathrm{Al}+\mathrm{SN}$ and $\mathrm{CN}+\mathrm{U}+\mathrm{SN}$.

It was noticed that urea had an inhibitory effect on mycelium weight and sclerotia formation, whereas, sodium nitrate, calcium nitrate and alanine were quite stimulatory for growth and sclerotia formation. 
Table.1 Response of $R$. solani towards different sources of carbon

\begin{tabular}{|c|c|l|c|c|c|}
\hline $\begin{array}{c}\text { SI. } \\
\text { No. }\end{array}$ & Treatments & \multicolumn{1}{|c|}{$\begin{array}{c}\text { Sources of } \\
\text { Carbon }\end{array}$} & $\begin{array}{c}\text { Amounts } \\
(\mathrm{g} / \mathrm{L})\end{array}$ & $\begin{array}{c}\text { Weight of dried } \\
\text { mycelium (mg) }\end{array}$ & $\begin{array}{c}\text { Sclerotia } \\
\text { formation }\end{array}$ \\
\hline $\mathbf{1}$ & $\mathrm{T}_{1}$ & Glucose & 31.56 & 271.25 & ++++ \\
\hline $\mathbf{2}$ & $\mathrm{T}_{2}$ & Lactose & 31.56 & 123.50 & Nil \\
\hline $\mathbf{3}$ & $\mathrm{T}_{3}$ & Maltose & 31.56 & 183.00 & ++ \\
\hline 4 & $\mathrm{~T}_{4}$ & Sucrose (Check) & 30.00 & 270.50 & +++ \\
\hline & & CD at 5\% & & 10.38 & \\
\hline
\end{tabular}

Table.2 Response of $R$. solani towards different sources of nitrogen

\begin{tabular}{|c|c|l|c|c|c|}
\hline $\begin{array}{c}\text { Sl. } \\
\text { No. }\end{array}$ & Treatments & \multicolumn{1}{|c|}{$\begin{array}{c}\text { Sources of } \\
\text { Nitrogen }\end{array}$} & $\begin{array}{c}\text { Amounts } \\
(\mathrm{g} / \mathrm{L})\end{array}$ & $\begin{array}{c}\text { Weight of dried } \\
\text { mycelium }(\mathbf{m g})\end{array}$ & $\begin{array}{c}\text { Sclerotia } \\
\text { formation }\end{array}$ \\
\hline $\mathbf{1}$ & $\mathrm{T}_{1}$ & Calcium Nitrate & 2.80 & 641.25 & ++++ \\
\hline $\mathbf{2}$ & $\mathrm{T}_{2}$ & Urea & 0.70 & 245.50 & Nil \\
\hline 3 & $\mathrm{~T}_{3}$ & Alanine & 2.08 & 433.50 & ++ \\
\hline 4 & $\mathrm{~T}_{4}$ & Sodium Nitrate (Check) & 2.00 & 270.50 & +++ \\
\hline & & & $\mathbf{1 0 . 1 4}$ & \\
\hline
\end{tabular}

Table.3 Response of $R$. solani towards different vitamins

\begin{tabular}{|c|c|l|c|c|c|}
\hline $\begin{array}{c}\text { SI. } \\
\text { No. }\end{array}$ & Treatments & \multicolumn{1}{|c|}{ Vitamins } & Amounts & $\begin{array}{c}\text { Weight of dried } \\
\text { mycelium }(m g)\end{array}$ & $\begin{array}{c}\text { Sclerotia } \\
\text { formation }\end{array}$ \\
\hline 1 & $\mathrm{~T}_{1}$ & Thiamine & $100(\mu \mathrm{g} / \mathrm{L})$ & 630.25 & ++++ \\
\hline 2 & $\mathrm{~T}_{2}$ & Biotin & $5(\mu \mathrm{g} / \mathrm{L})$ & 234.75 & Nil \\
\hline 3 & $\mathrm{~T}_{3}$ & Inositol & $500(\mu \mathrm{g} / \mathrm{L})$ & 226.25 & + \\
\hline 4 & $\mathrm{~T}_{4}$ & Yeast extract (Check) I & $2(\mathrm{~g} / \mathrm{L})$ & 344.00 & +++ \\
\hline 5 & $\mathrm{~T}_{5}$ & (Czapek's) (Check) II & & 270.50 & +++ \\
\hline & & CD at 5\% & & 10.38 & \\
\hline
\end{tabular}

Table.4 Response of $R$. solani towards different combinations of carbon sources

\begin{tabular}{|c|c|l|c|c|}
$\begin{array}{c}\text { SI. } \\
\text { No. }\end{array}$ & Treatments & \multicolumn{1}{|c|}{ Combination of Carbon sources } & $\begin{array}{c}\text { Weight of dried } \\
\text { mycelium (mg) }\end{array}$ & $\begin{array}{c}\text { Sclerotia } \\
\text { formation }\end{array}$ \\
\hline $\mathbf{1}$ & $\mathrm{T}_{1}$ & Sucrose + Fructose + Lactose + Glucose & 295.00 & +++ \\
\hline $\mathbf{2}$ & $\mathrm{T}_{2}$ & Sucrose + Fructose + Lactose & 351.00 & ++++ \\
\hline 3 & $\mathrm{~T}_{3}$ & Sucrose + Fructose + Glucose & 225.00 & + \\
\hline $\mathbf{4}$ & $\mathrm{T}_{4}$ & Sucrose + Lactose + Glucose & 240.00 & + \\
\hline $\mathbf{5}$ & $\mathrm{T}_{5}$ & Fructose + Glucose + Lactose & 390.00 & ++++ \\
\hline 6 & $\mathrm{~T}_{6}$ & Check (Czapek's) & 272.00 & +++ \\
\hline & & CD at 5\% & $\mathbf{1 2 . 8 4}$ & \\
\hline
\end{tabular}


Table.5 Response of $R$. solani towards different combinations of nitrogen sources

\begin{tabular}{|c|c|c|c|c|}
\hline $\begin{array}{l}\text { Sl. } \\
\text { No. }\end{array}$ & Treatments & Vitamin combinations & $\begin{array}{l}\text { Weight of dried } \\
\text { mycelium (mg) }\end{array}$ & $\begin{array}{l}\text { Sclerotia } \\
\text { formation }\end{array}$ \\
\hline 1 & $\mathrm{~T}_{1}$ & $\begin{array}{l}\text { Calcium Nitrate }+ \text { Urea }+ \text { Alanine }+ \text { Sodium } \\
\text { Nitrate }\end{array}$ & 680.50 & +++ \\
\hline 2 & $\mathrm{~T}_{2}$ & Calcium Nitrate + Urea + Alanine & 275.00 & ++ \\
\hline 3 & $\mathrm{~T}_{3}$ & Calcium Nitrate + Urea + Sodium Nitrate & 290.00 & ++++ \\
\hline 4 & $\mathrm{~T}_{4}$ & Calcium Nitrate + Alanine + Sodium Nitrate & 860.00 & +++++ \\
\hline 5 & $\mathrm{~T}_{5}$ & Urea+ Alanine + Sodium Nitrate & 310.00 & ++ \\
\hline \multirow[t]{2}{*}{6} & T6 & Check (Czapek's medium) & 270.50 & +++ \\
\hline & & CD at $5 \%$ & 18.78 & \\
\hline
\end{tabular}

Table.6 Response of $R$. solani towards different combinations of vitamins

\begin{tabular}{|c|c|l|c|c|}
$\begin{array}{c}\text { S. } \\
\text { No. }\end{array}$ & Treatments & \multicolumn{1}{|c|}{ Vitamin combinations } & $\begin{array}{c}\text { Weight of dried } \\
\text { mycelium (mg) }\end{array}$ & $\begin{array}{c}\text { Sclerotia } \\
\text { formation }\end{array}$ \\
\hline 1 & $\mathrm{~T}_{1}$ & $\begin{array}{l}\text { Calcium pentothenate + Thiamine + Inositol } \\
\text { + Biotin }\end{array}$ & 321.50 & +++ \\
\hline 2 & $\mathrm{~T}_{2}$ & Biotin + Inositol + Thiamine & 170.00 & ++ \\
\hline 3 & $\mathrm{~T}_{3}$ & Biotin + Calcium pentothenate + Thiamine & 450.00 & ++++ \\
\hline $\mathbf{4}$ & $\mathrm{T}_{4}$ & Calcium pentothenate +Inositol + Thiamine & 192.00 & + \\
\hline 5 & $\mathrm{~T}_{5}$ & Calcium pentothenate + Inositol + Biotin & 155.00 & ++ \\
\hline 6 & $\mathrm{~T}_{6}$ & Yeast extract & 361.00 & +++++ \\
\hline & $\mathrm{T} 7$ & Check (without vitamin) & 265.00 & +++ \\
\hline & & CD at 5\% & 16.78 & \\
\hline
\end{tabular}

Effect of different combinations of vitamins on $R$. solani

Among the various combinations of vitamin, Biotin (B) + Calcium pentothenate (C.) + Thiamine (T) was found to support highest weight of dried mycelium i.e. $450.00 \mathrm{mg}$ followed by yeast extract i.e. $361.00 \mathrm{mg}$ (Table 5). The weight of dried mycelium supported by the combination of $\mathrm{B}+\mathrm{C}+\mathrm{T}$ was significantly higher than the weight of dried mycelium supported by yeasty extract supplemented medium. The combination of vitamins such as $\mathrm{B}+\mathrm{I}+\mathrm{T}, \mathrm{C}+\mathrm{I}+\mathrm{T}$ and $\mathrm{C}+\mathrm{I}+\mathrm{B}$, seems to be inhibitory for growth because the weight of dried mycelium recorded in these three combinations were significantly less than the weight of dried mycelium obtained in basal medium without any vitamin supplement. The highest number, larger size, bright yellow colored sclerotia were produced in yeast extract supplemented medium.

The combination of $\mathrm{B}+\mathrm{C}+\mathrm{T}$ also supported quite higher number of sclerotia, but comparatively lesser and smaller in size than the sclerotia produced in the medium supplemented with yeast extract. The combinations of all four vitamins supported third highest number of sclerotia, whereas the medium supplemented with $\mathrm{B}+\mathrm{I}+\mathrm{T}, \mathrm{C}+\mathrm{I}+\mathrm{B}$, yeast extract or without vitamin supported the reduced number of sclerotia. The least number of sclerotia was recorded in the medium supplemented with combination of Calcium pentothenate, Inositol and Thiamine. 
Response of $R$. solani towards different sources of carbon

Among the carbon sources tested for their suitability to growth and sclerotia formation of $R$. solani, glucose supported highest weight of dried mycelium and sclerotia formation followed by sucrose (check) and maltose. The least weight of dried mycelium was observed in media containing lactose which did not support sclerotia formation. Misawa (1965) reported that monosaccharide promoted better growth than disaccharides but some polysaccharides gave the best growth. Bilgrami (1967) reported that out of the component of monosaccharide i.e. glucose and fructose, the utilization of glucose fraction was comparatively rapid. Tandon (1967) reported that sucrose is good carbon source for plant pathogenic fungi. Sharma and Tripathi (2002) reported that dextrose as carbon source resulted in the greatest mycelial growth followed by mannitol and sorbitol. Mycelial growth was inhibited in starch, galactose and lactose after $144 \mathrm{~h}$ of inoculation. Dextrose resulted in the highest number of sclerotia followed by mannitol and sorbitol in urd bean isolate of $R$. solani. Thus, the findings of present investigation are quite in conformity with the reports of earlier workers.

\section{Response of $R$. solani towards different sources of nitrogen}

Among the nitrogen sources, calcium nitrate supported highest mycelial weight and sclerotia formation. Second highest mycelial weight was observed in alanine followed by sodium nitrate (check), the least mycelial weight was noticed in media containing urea with no sclerotia formation. Formation of sclerotia was higher in calcium nitrate and sodium nitrate than alanine. In general, nitrates are excellent sources for imperfect fungi and ascomycetes (Bilgrami, 1964;
Tandon, 1967; Narasimhan, 1969; Subramanian and Tyagi, 1968). Tandan (1967) reported that potassium nitrate, calcium nitrate and sodium nitrate were generally utilized by imperfect fungi. The findings of these workers are quite supportive to the present findings. Muller (1924) also observed that amino acids as sources of nitrogen have also been found to support growth of $R$. solani, these included alanine, asparagine, leucine and tyrosine. During present investigation also alanine supported good growth of $R$. solani. According to Chauhan (2006) the calcium nitrate supported good growth of Bipolaris sorokiniana. This also indicates that $B$. sorokiniana and $R$. solani (both are imperfect fungi) have similar preference for sources of nitrogen.

\section{Response of $R$. solani towards different vitamins}

Among different vitamins, the thiamine supported highest fungal growth and sclerotia formation followed by yeast extract (source of multivitamins) and czapek's medium without any supplement (Check II). The least growth and sclerotia formation was observed in media containing inositol. The growth obtained in inositol was at par with growth resulted from medium containing biotin. There was no sclerotia formation in medium containing biotin. Madan and Thind (1998) reported that vitamins are constituents or precursors of co-enzymes and are required in small quantities by the living organisms for their normal growth and reproduction. Some fungi are able to synthesize all vitamins which they require, others do not have the system for the synthesis of vitamins they requires and one or more vitamins have to be supplied externally for their normal growth. Jandaik and Kapoor (1972) found that there was poor growth when all the vitamins or thiamine were omitted from the medium, which is in support of present investigation as thiamine alone produced highest growth in present 
findings. According to Bilgrami (1963), Tandon (1967) and Norkrans (1950) thiamine is required by many imperfect fungi for their optimum growth. During present investigation also thiamine supported highest mycelial growth thus it is quite in support of earlier findings of these workers. According to Chauhan (2006) who worked on B. sorokiniana, another imperfect fungus, the biotin and inositol were found least effective, which supports the findings of present investigation as inositol and biotin were found to be inhibitory for $R$. solani during present investigation.

\section{Response of $R$. solani towards different combinations of carbon sources}

Among the different combinations of carbon sources viz., sucrose $(\mathrm{S})+$ fructose $(\mathrm{F})+$ lactose $(\mathrm{L})+$ glucose $(\mathrm{G}), \mathrm{S}+\mathrm{F}+\mathrm{L}, \mathrm{S}+\mathrm{F}+\mathrm{G}, \mathrm{S}+\mathrm{L}+\mathrm{G}$ and $\mathrm{F}+\mathrm{G}+\mathrm{L}$ tested for their suitability for growth and sclerotia formation of $R$. solani.

The combination of $\mathrm{F}+\mathrm{G}+\mathrm{L}$ resulted in highest weight of dried mycelium and number of sclerotia followed by $\mathrm{S}+\mathrm{F}+\mathrm{L}$. However, combination of $\mathrm{S}+\mathrm{F}+\mathrm{G}$ at the similar concentration resulted in least weight of dried mycelium and poor sclerotia formation. Through several previous findings it is recommended that Czapek's medium is suitable for growth and sclerotia formation of $R$. solani, in which sucrose is added as a carbon source.

From the findings it is evident that presence of fructose and lactose together has a stimulatory effect on growth and sclerotia formation of $R$. solani as simultaneous supply of these two constituents resulted in highest mycelial weight and sclerotia formation. There is no earlier report regarding effect of combinations of carbon sources on $R$. solani but several workers has tested these sugars as individual supplement. Singh (2006) reported fructose as best carbon source for growth and sclerotia formation of $R$. solani which partially support the findings of present investigations. Sharma and Tripathi (2002) found dextrose to support the greatest mycelial growth and highest number of sclerotia. Misawa (1965) reported that monosaccharide promoted better growth than disaccharides, but some polysaccharides, gave the best growth of $R$. solani fungus. This report also supports our findings because fructose is a monosaccharide which has a stimulatory effect on growth and sclerotia formation of $R$. solani.

\section{Response of $R$. solani towards different combinations of nitrogen sources}

Among the various combinations of nitrogen sources, viz. calcium nitrate $(\mathrm{CN})+$ alanine $(\mathrm{Al})$ + sodium nitrate $(\mathrm{SN})+$ urea $(\mathrm{U}), \mathrm{CN}+\mathrm{Al}+\mathrm{SN}$ supported highest weight of dried mycelium followed by the combination $\mathrm{CN}+\mathrm{Al}+\mathrm{SN}+\mathrm{U}$. Maximum number of sclerotia was noticed in the combination $\mathrm{CN}+\mathrm{Al}+\mathrm{SN}$ and $\mathrm{CN}+\mathrm{U}+\mathrm{SN}$. It was noticed that urea had an inhibitory effect on mycelium weight and sclerotia formation, whereas Sodium nitrate, calcium nitrate and alanine were quite stimulatory for growth and sclerotia formation. The reason behind this may be that nitrates are chiefly and better utilized by imperfect fungus. Alanine being an amino acid is also very supportive for better growth and sclerotia formation of $R$. solani, as it is an amino acid which may also be stimulatory for growth behavior.

The findings are also supported by the reports of previous workers as nitrates are excellent sources for imperfect fungi and ascomycetes (Subramanian, 1968, Narasimhan, 1969 and Chauhan, 2006). Muller (1924) reported that alanine support the growth of $R$. solani.

\section{Response of $R$. solani towards different combinations of vitamins}

Among the different combinations of vitamins (Table 5), maximum weight of dried mycelium was obtained in the basal medium supplemented with $\mathrm{B}+\mathrm{C}+\mathrm{T}$ followed by yeast extract, whereas maximum sclerotia was recorded due to yeast extract followed by medium supplemented with $\mathrm{B}+\mathrm{C}+\mathrm{T}$ followed by yeast extract supplemented medium. However, highest number of sclerotia 
was noticed in yeast extract supplemented medium and combination of $\mathrm{B}+\mathrm{C}+\mathrm{T}$ was seems to next one to produce sclerotia. The least weight of dried mycelium and number of sclerotia was recorded in combinations $\mathrm{C}+\mathrm{I}+\mathrm{B}$ and $\mathrm{B}+\mathrm{I}+\mathrm{T}$, respectively. Jandaik and Kapoor (1972) studied the effect of 9 vitamins on the growth and sporulation of Cercospora cruenta. They found that there was maximum growth when all the vitamins were presented. Munjal and Gautam (1977) tested different vitamins for their effect on growth and sporulation of Septoria humili.

They found minimum growth when either all vitamin (combination) or thiamine alone was omitted from the mixture of vitamins. Chauhan (2006) also tested four vitamins against isolates of $B$. sorokiniana. He found that all isolates exhibited maximum growth on thiamine whereas the maximum sporulation was noticed due to yeast extract. The vitamin, Inositol and calcium pentothenate was found to be inhibitory for growth of all isolates. Findings of present investigation is partially supported by Chauhan (2006) as thiamine induced the growth of $R$. solani in present investigation, while, there was also difference in response towards calcium pentothenate, it may be due to differences in the vitamin requirement of two genera. According to Bilgrami (1963), Tandan (1967) and Narkrans (1950); thiamine is required by many imperfect fungi for their optimum growth. Biotin requirement among fungi appears to be next to thiamine. During present investigation, thiamine and biotin also had positive and stimulatory effect on growth of $R$. solani.

\section{References}

Bilgrami, K.S. 1963. Proc. Indian Acad, Sci. 58: 165-175.

Bilgrami, K.S. 1964. Flora. Bd. 154: 1-11.

Bilgrami, K.S. 1967. Bull. Natl. Inst. Sci. India 35, Symp. on Physiology of Fungi, Chandigarh.

Bolkan, H.A. and Ribeiro, W.R.C. 1985. Anastomosis groups and pathogenicity of
Rhizoctonia solani isolates from Brazil. Plant Disease 69: 599-601.

Chauhan, A. 2006. Studies on spot blotch disease of wheat with special reference to pathogenic variability and host resistance. Ph.D. (Ag.) Thesis. Dept. of Plant Pathology, N.D.U.A.T., Kumarganj, Faizabad - 224 229, U.P., 141 pp.

Dasgupta, M.K. 1992. Rice Sheath Blight: the challenge continues. In: Plant Diseases of International Importance: Diseases of cereals and pulses. Vol. I. (Eds. U.S. Singh, A.N. Mukhopadhyay, J. Kumar, H.S. Chaube). Prentice. Hall Englewood Chiefs, New Jersery, pp. 138-157.

Eizenga, G.C., Lee, F.N. and Rutger, J.N. 2002. Screening Oryza species plants for rice sheath blight resistance. Plant Disease 66: 808-812.

Gautam, K., Rao, P. B. and Chauhan, S. V. S., 2003. Efficacy of some botanicals of the family compositae against Rhizoctonia solani Kuhn. J. Mycol. and PlantPathol., 33: 230-235.

Hyakumachi, M. and Ui, T. 1982. The role of the over wintered plant debris and sclerotia as inoculum in the field occurred with sugarbeet root rot. Ann. Phytopath. Soc. Japan. 48: 623-628.

Jandaik, C.L. and Kapoor, J.N. 1972. Studies on vitamin requirement of Cercospora cruenta. Indian Phytopath. 25: 563-565.

Kotasthane, A.S., Agrawal, T., Shalini and Saluja, M. 2004. A specialized approach for managing on unspecialized fungus causing sheath blight disease in rice. International Symposium an Rainfed Rice Ecosystems: Perspective and Potential. pp 40. Indira Gandhi Agric. Univ., Raipur, Chhattisgarh, India.

Madan, M. and Thind, K. S. 1998. Physiology of fungi, A. P. H. Publishing Corporation, New Delhi, pp. 213.

Misawa, T. 1965. Nutritional factors for phytopathogenic fungi on culture media. Annals of the Phytopathological Socieity of Japan. 31: 27-34.

Muller, K.O. 1924. Untersuchungen zur Entwickelungsgeschichte und Biologie 
von Hypochnus solani P.U.D. (Rhizoctonia solani) Arbiet. Biol. Reichsanst. Land u. Forstw. 13: 198-262.

Munjal, R. I. and Gautam, S. R. 1977. Effect of vitamins on growth and sporulation of Septoria humuli. Indian Phytopathology. 33: 566-567.

Narasimhan, 1969. Indian Phytopathalogy. 22: 115-123.

Norkrans, B. 1950. Symbolae Botan. Upsalienses 11: 1-126.

Parmeter, J.R. and Whitney, H.S. 1970. Taxonomy and nomenclature of the imperfect state- Rhizoctonia solani. In: (Ed. J.R. Parmeter). Biology and Pathology. University of California Press, Berkley University of California Press, Berkelay, Los Angeles and London.

Ramakrishnan, T.S. 1971. Diseases of rice. Indian Council of Agriculture Research, New Delhi p. 150.

Rashmi-Rohilla., Singh, R.L., Singh, U.S., Singh, H.B. 2001. Recent advances in the management of plant diseases using chemicals.

Richa, K., Tiwari, I. M., Kumari, M., Devanna, B. N., Sonah, H., Kumari, A., Nagar, R., Sharma, V., Botel, J. R. and Sharma, T. R. 2016. Functional Characterization of Novel Chitinase Genes Present in the Sheath Blight Resistance QTL: qSBR111in Rice Line Tetep. Frontiers in Plant Science, 7: 1-10.

Roy, A.K. 1993. Sheath blight of rice in India. Indian Phytopathology 46: 197-205.

Savary S. and Mew T. W. 1996. Analyzing crop losses due to Rhizoctonia solani: rice sheath blight, a case study. In: Sneh B, Javaji-Hare S, Neate S, Dijst G (Eds) Rhizoctonia species: taxonomy, molecular biology, ecology, pathology and disease control, Kluwer, Dordrecht, pp 237-244.

Sharma, J. and Tripathi, H.S. 2002. In-vitro response of urd bean isolate of $R$. solani to different carbon and nitrogen sources. Indian J. of Pulses Res. 15: 199-200.

Singh, B.P. 2006. Effect of carbon and nitrogen sources on Rhizoctonia solani and its integrated management. M.Sc. (Ag.) Thesis. Dept. of Plant Pathology, N.D.U.A.T., Kumarganj, Faizabad - 224 229, U.P., 72 pp.

Singh, N.I., Devi, R.K.T. and Singh, K.U. 1989. $R$. solani an agent of rice boot blight. Int. Rice Res. Newsl. 14: 22.

Skamnioti, P. and Gurr, S. J. 2009. Against the grain: safeguarding rice from rice blast disease. Trends in Biotechnology, 27: 141-150.

Starr, M.P. 1984. Landmarks in development of phytobacteriology. Annual Review of Phytopathology, 22: 169-188.

Subramanian, C.V. and Tyagi, P.D. 1968. Proc. Indian Acad. Sci. 58: 11-129.

Tandon, 1967. Presidential address, $54^{\text {th }}$ Indian Science Congress. pp. 1-14.

Wopereis, M. C. S., Defoer, T., Idinoba, P., Diack, S. and Dugue, M. J., 2009. Curriculum for participatory learning and action research (PLAR) for integrated rice management (IRM) in inland valleys of Sub-Saharan Africa. Technical Manual, 105-109.

\section{How to cite this article:}

Durga Prasad, Ramji Singh and Ajay Tomer. 2018. Physiology of Rice Sheath Blight Pathogen Rhizoctonia solani Kuhn towards Different Sources of Carbon, Nitrogen and Vitamins. Int.J.Curr.Microbiol.App.Sci. 7(08): 1805-1815. doi: https://doi.org/10.20546/ijcmas.2018.708.207 